\title{
HSP: bystander antigen in atopic diseases?
}

\author{
Joost A. Aalberse ${ }^{1}{ }^{*}$, Berent J. Prakken ${ }^{1 *}$ and Berber Kapitein ${ }^{2}$ \\ ${ }^{1}$ Department of Pediatric Immunology, Center for Molecular and Cellular Intervention, Wilhelmina Children's Hospital, University Medical Center, Utrecht, \\ Netherlands \\ 2 Pediatric Intensive Care Unit, Sophia Children's Hospital, Rotterdam, Netherlands
}

\section{Edited by:}

Willem Van Eden, Utrecht University, Netherlands

\section{Reviewed by:}

Miriam Wittmann, University of Leeds, UK

Cristina Bonorino, Pontificia

Universidade Catolica do Rio Grande

do Sul, Brazil

\section{*Correspondence:}

Joost A. Aalberse and Berent J. Prakken, Wilhelmina Children's Department of Pediatric Immunology, Center for Molecular and Cellular Intervention, Eureka Institute for Translational Medicine, KC.03.063.0, PO Box 85090, Utrecht, The Netherlands.

e-mail: jaalber2@umcutrecht.nl; bprakken@umcutrecht.n Hospital, University Medical Centre,

Over the last years insight in the complex interactions between innate and adaptive immunity in the regulation of an inflammatory response has increased enormously. This has revived the interest in stress proteins; proteins that are expressed during cell stress. As these proteins can attract and trigger an immunological response they can act as important mediators in this interaction. In this respect, of special interest are proteins that may act as modulators of both innate and adaptive immunity. Heat shock proteins (HSPs) are stress proteins that have these, and more, characteristics. More than two decades of studies on HSPs has revealed that they are part of intrinsic, "natural" mechanisms that steer inflammation. This has provoked comprehensive explorations of the role of HSPs in various human inflammatory diseases. Most studies have focused on classical autoimmune diseases. This has led to the development of clinical studies with HSPs that have shown promise in Phase II/II clinical trials. Remarkably, only very little is yet known of the role of HSPs in atopic diseases. In allergic disease a number of studies have investigated the possibility that allergen-specific regulatory $T$ cell (Treg) function is defective in individuals with allergic diseases. This raises the question whether methods can be identified to improve the Treg repertoire. Studies from other inflammatory diseases have suggested HSPs may have such a beneficial effect on the T cell repertoire. Based on the immune mechanisms of atopic diseases, in this review we will argue that, as in other human inflammatory conditions, understanding immunity to HSPs is likely also relevant for atopic diseases. Specifically, we will discuss why certain HSPs such as HSP60 connect the immune response to environmental antigens with regulation of the inflammatory response. Thus they provide a molecular link that may eventually even help to better understand the immune pathological basis of the hygiene hypothesis.

Keywords: allergic disease, atopic disease, stress proteins, heat shock protein, HSP60, regulatory T cells, hygiene hypothesis, inflammation

\section{INTRODUCTION}

Over the last years insight in the complex interactions between innate and adaptive immunity in the regulation of an inflammatory response has increased enormously. This has revived the interest in stress proteins; proteins that are expressed during cell stress. As these proteins can attract and trigger an immunological response they can act as important mediators in this interaction. In this respect, of special interest are proteins that may act as modulators of both innate and adaptive immunity. Heat shock proteins (HSPs) are stress proteins that have these, and more, characteristics. More than two decades of studies on HSPs has revealed that they are part of intrinsic, "natural" mechanisms that steer an inflammatory response (Pockley, 2003; van Eden et al., 2005). This has provoked comprehensive explorations of the role of HSPs in various human inflammatory diseases. Most of these studies have focused on classical autoimmune diseases such as type I diabetes (IDDM), rheumatoid arthritis (RA), and juvenile idiopathic arthritis (JIA; Abulafia-Lapid et al., 1999; de Kleer et al., 2003, 2004). This has led to the development of clinical studies with HSPs that have shown promise in Phase II/III clinical trials in both IDDM and RA (Albani et al., 1995a; Raz et al., 2001; Prakken et al., 2004).

Remarkably, only very little is yet known of the role of HSPs in atopic diseases. Based on the immune mechanisms of atopic diseases, in this review we will argue that, as in other human inflammatory conditions, understanding immunity to HSPs is likely also relevant for atopic diseases. Specifically, we will discuss why certain HSPs such as HSP60 connect the immune response to environmental antigens with regulation of the inflammatory response. Thus, they provide a molecular link that may eventually even help to better understand the immune pathological basis of the hygiene hypothesis: an important concept relating the increase in the prevalence of atopic disease with exposure to microbes or microbial products early in life.

\section{ALLERGY}

Atopy is the predisposition to develop allergic diseases like atopic dermatitis, food allergy, asthma, and allergic rhinitis. It is characterized by a predominant typical T helper 2 (Th2)-like immune response (Umetsu et al., 2003). Firstly, an environmental allergen, 
like an inhalant or food allergen interacts with the innate immune system. After uptake by antigen-presenting cells, subsequent $\mathrm{T}$ cell priming leads to the stimulation of type 2 cytokines such as interleukin (IL)-4, IL-5, and IL-13. These cytokines interact with their receptors to induce a class switch toward $\operatorname{IgE}$ production and to increase the number of eosinophils and mast cells. In immediate hypersensitivity reactions IgE binds to its receptors and causes mast cells to degranulate. Apart from IgE, increased levels of IgG4 are often measured in allergic individuals. IgG4 is considered as an antibody with anti-inflammatory activity (van der Neut et al., 2007). The levels of IgG4 are usually elevated in serum from people that are repeatedly exposed to the same antigen, like beekeepers, or subjects receiving increased doses of antigen during specific immune therapy (SIT). In addition to this humoral immune response, allergy is characterized by a cellular response, mostly mediated by Th2 cells (Del Prete, 1992; Ozdemir et al., 2010), but also by Th1 cells (like in atopic dermatitis) and regulatory $\mathrm{T}$ cells.

The combination of these humoral and cellular responses, both innate and adaptive, leads to an allergic inflammatory reaction (Yazdanbakhsh et al., 2002). Here we will discuss various aspects of the allergic immune responses in the context of the possible role of environmental antigens such as HSPs in steering this immune response.

\section{ALLERGY AND THE HYGIENE HYPOTHESIS}

The prevalence of atopic disease has increased tremendously in the second half of the twentieth century (Peat et al., 1994). Although the cause of this increase is not known though, a genetic cause is unlikely due to the time span in which the increase took place. Therefore environmental changes are more likely causes of this observed increase. Strachan (1989) first proposed the concept of the hygiene hypothesis. This hypothesis states that the increase in the prevalence of atopic disease is due to a decreased exposure to microbes or microbial products early in life, especially in western societies. The concept was supported by the observation of an inverse association between both atopic dermatitis and hay fever and the number of children in a household. Although the hygiene hypothesis and its proposed immune mechanism are still under debate, in the 1990s numerous of studies have been published supporting this hypothesis. For example, these observations relate the number of siblings, the number of infections and exposure to endotoxins on the farm, with the incidence of atopic diseases (Jarvis et al., 1997; Bodner et al., 1998; von Mutius et al., 1999; Wickens et al., 1999; Braun-Fahrlander et al., 2002).

\section{IMMUNE MECHANISMS OF THE HYGIENE HYPOTHESIS}

What could be the immunological cause of this inverse relation between exposure to environmental antigens and the incidence of allergic disease? The explanation takes us back to the original observations in the eighties of Mosmann and Coffman who defined two main subtypes of helper T lymphocytes: Th1 and Th2 cells. Th2 cells are characterized by their production of cytokines like IL-4, IL-5, IL-9, and IL-13 and chemokines like TARC and MDC. They are involved in mediating allergic responses and host defense against parasitic infection (Mosmann and Coffman, 1989).

During fetal life and shortly after birth a predominant Th2 response is present (Wegmann et al., 1993). During life, a shift to a predominant Th1 response occurs in non-allergic subjects, but this shift may be incomplete in allergic individuals. As a consequence, an allergic individual will develop a Th2 response to an allergen leading to IgE production and typical type 2 cytokine production (IL-4, IL-5, and IL-13) and ultimately to a clinical allergic reaction, whereas non-allergic subjects develop a Th1 response leading to a protective IgG response and production of IFN- $\gamma$ (Larche, 2007). This is the basis for the immunological explanation of the hygiene hypothesis, as exposure to microbes and microbial products would stimulate a Th1 response. Those individuals that were not enough exposed to these stress factors would be more prone to develop predominant Th2 responses, and thus an allergic response. Obviously this is still a simplification of the immune pathogenesis that does not explain all observations. For example, a Th1 response in allergic individuals would implicate the development of late hypersensitivity responses, whereas healthy individuals do not respond to allergens with a clinically noticeable response (Chen et al., 2004).

The hygiene hypothesis also does not explain why not only the incidence of allergic diseases is increasing but also that of auto immune diseases like RA and IDDM (Sheikh et al., 2003). These diseases are obviously known as typical Th1-like diseases.

\section{TRIGGERING AN ALLERGIC IMMUNE RESPONSE}

In order to fully assess and better appreciate the value of the hygiene hypothesis it is important to understand which cells are responsible for the initial trigger leading to the characteristic allergic immune response. First, naive T cells have to be activated, in a way that promotes the classical Th2 like response. There is recent evidence that basophils may play a crucial role in antigen recognition and processing. When recruited to lymph nodes they are able to induce Th2 cell differentiation through the release of IL4 (Sokol et al., 2009; Falcone et al., 2011). Other cells also have the capacity to process and present allergens, including mast cells, macrophages, eosinophils, and natural helper cells. Natural helper cells are innate cell populations that include innate Th2 cells and are activated by IL-25 and IL-33 to secrete Th2 cytokines (Saenz et al., 2010).

There is an increasing realization that Th2 cells are not the only cells involved in the pathophysiology of allergic disease, as particularly in severe disease other cells than Th2 play a role in aggravating and perpetuating the immune response (Table 1; Lloyd and Hessel, 2010).

First of all, whereas Th2 cytokines have a clear role in initiating an allergic response, especially Th1 cells have been implicated in more chronic severe allergic disease, both in atopic dermatitis and allergic asthma (Krug et al., 1996; Ong and Leung, 2006; Yamanaka and Mizutani, 2011).

Secondly, in addition to the Th2 cytokines IL-4, IL-5, and IL13, recently also IL-9 was shown to play an important role in asthma. At first IL-9 was discussed as a new Th2 cytokine. It was shown that Th9 cells are dependent on both IL-4 and transforming growth factor-beta (TGF- $\beta$ ) for their development. Interestingly, like Th2 cells, also Th9 cells are regulated by IL-25, predominantly seen in lung inflammation (Devos et al., 2006; Hauber et al., 2007; Soroosh and Doherty, 2009; Angkasekwinai et al., 2010). IL-25 (like IL-33 and thymic stromal lymphopoietin) is a type II initiating cytokine (Oliphant et al., 2011). In addition to the role of 
Table 1 | Different subtypes described to play a role in the pathogenesis of allergic diseases.

\begin{tabular}{lllll}
\hline Cell & Main transcription factor & Activating cytokines & Effector cytokines & Role in allergic diseases \\
\hline Th1 & T-Bet & IL-12 & IFNy & Possible role in chronic asthma or atopic dermatitis \\
Th2 & GATA-3 & IL-4, IL-25, IL-33, TSLP & IL-4, IL-5, IL-13, IL-25 & Eosinophil production; IgE induction \\
Th9 & PU-1 & IL-4, TGF $\beta$, IL-10, IL-25 & IL-9, IL-10 & Mucus production, lung inflammation, dermatitis \\
Th17 & Batf & TGF $\beta$, IL-1 $\beta$ IL-6, IL-21 & IL-6, IL-8, IL-17, IL-22 & $\begin{array}{l}\text { Possibly related to steroid resistant asthma; related to neutrophil } \\
\text { production }\end{array}$ \\
Th22 & RORyT(?) & ? & IL-22 & $\begin{array}{l}\text { Limiting airway inflammation in mice. Negative association with } \\
\text { Th2 cytokines }\end{array}$ \\
Tr1 & FOXP3 & TGF $\beta$ & IL-5, IL-10, IL-13, TGF $\beta$ & $\begin{array}{l}\text { Regulatory function on B cells by suppression of allergen-specific } \\
\text { IgE and induction of IgG4 and IgA }\end{array}$ \\
Tregs & FOXP3 & Diminished function and number in allergic individuals
\end{tabular}

IL-25 in lung inflammation, it is also of importance in atopic dermatitis and food allergy (Aalberse et al. unpublished data; Hvid et al., 2011). Although IL-25 (also known as IL-17E) is a cytokine from the IL-17 family it has opposite effects of IL17A (IL-17).

Thirdly, Th17 cells (named after their main effector cytokine; IL-17) like Th1 cells may be associated with more severe asthma and mediate a more neutrophilic pattern of inflammation.

Fourthly, it was recently shown that IL-22 (also produced by Th17 cells), is produced by a distinct set of CD4+ cells, named Th22-cells. These cells have been implicated as being protective in a mouse model of allergic lung inflammation (Souwer et al., 2010) and may play a role in the severity of atopic dermatitis in humans (Nograles et al., 2009).

Finally, a lot of attention has recently focused on a subset of $\mathrm{T}$ cells with the capacity to suppress other $\mathrm{T}$ cells, namely regulatory $\mathrm{T}$ cells (Treg). Two types of regulatory $\mathrm{T}$ cells will be discussed below, namely IL-10 producing regulatory cells and FOXP3 expressing regulatory cells.

\section{REGULATORY T CELLS}

Here we will discuss two types of regulatory $\mathrm{T}$ cells; FOXP3 expressing Tregs and IL-10 producing regulatory T cells. However, it has to be emphasized that the distinction between these two types is not absolute, as for example FOXP3 expressing Tregs are also capable of producing IL-10. Moreover, many different regulatory $\mathrm{T}$ cells, may even act in concert in a single immune response.

\section{IL-10 PRODUCING REGULATORY T CELLS}

As discussed above, exposure to an allergen leads to the development of sensitization in a susceptible individual. Upon a next encounter, a typical Th2 reaction will follow, including a humoral (IgE and IgG4) response. In contrast, when healthy (non-allergic) individuals are exposed to an allergen it was long thought that (in line with the Th1/Th2 dichotomy) instead of a Th2 response a Th1 response would develop. However it has become clear that, in fact, this is not the only difference between a normal and an allergic response to an allergen. Though indeed some IFN- $\gamma$ responses to allergens are present in healthy individuals, a study by Akdis et al. (2004) showed that this is a simplification of the reality. They isolated CD4 T cells specific to several food- and aeroallergens from healthy and allergic individuals according to their IL-4, IFN- $\gamma$, and IL-10 secretion profile. Interestingly, allergen-specific $\mathrm{T}$ cells that belong to all three secretion profiles were detectable in both healthy and allergic individuals, with allergen-specific IL-10-secreting $\mathrm{T}$ cells being the predominant subset in healthy individuals. They regarded these IL-10 producing CD4 $+\mathrm{T}$ cells as T regulatory cell type 1 ( $\operatorname{Tr} 1$ cells). Seemingly, low $\operatorname{Tr} 1$ numbers and high Th2 cell numbers resulted in an allergic response, whereas in healthy individuals a mixed Th1/Th2 response is associated with a strong IL-10 response (Larche, 2007). The crucial role for IL-10 in allergy is also suggested by other studies on food and inhalant allergies. In cow's milk allergy, T-cell clones derived from children that are persistently allergic produced Th2 cytokines (IL-4, IL-13), whereas allergic control subjects that are cow milk tolerant produced a mixed Th1/Th2 response associated with markedly elevated IL-10 levels (Tiemessen et al., 2004).

Similar observations of elevated IL-10 levels associated with less allergy symptoms were made in inhalation allergies. Children raised in a house with a cat are less likely to become allergic to cat allergen than those who only get indirect exposure. Many of these highly exposed children had an IgG and IgG4 response to the major cat allergen Fel d 1 without production of specific IgE. This induction of high levels of allergen-specific IgG4 in the relative absence of IgE has been referred to as a modified Th2 response (Platts-Mills et al., 2004). Interestingly also in the peripheral blood of these non-allergic children, $\mathrm{T}$ cell response to the allergens are characterized by an elevated level of IL-10. Comparable indications for a role for IL-10-producing $\operatorname{Tr} 1$ cells in the maintenance of tolerance to allergens can be found in individuals exposed to relatively high doses of allergen like bee keepers and allergic patients undergoing immunotherapy. Bee keepers with a repeated exposure to bee venom during the bee-keeping season demonstrate a marked increase in allergen-specific IL-10 secretion from peripheral blood $\mathrm{T}$ cells as the season progresses, while allergen-specific $\mathrm{IgE}$ is seen especially in the beginning of the season. Interestingly, reactions to stings disappear during the season, simultaneously with the increased IL-10 production by T-cells (Akdis and Blaser, 1999). Apart from IL-10, also TGF- $\beta$, another cytokine that can be produced by $\operatorname{Tr} 1$ cells, is reported to be induced by SIT, while both IL-10 and TGF- $\beta$ are associated respectively with the blocking antibodies IgG4 and IgA (Larche et al., 2006; Taylor et al., 2006). 


\section{FOXP3 REGULATORY T CELLS}

Not only IL-10 producing T cells but also FOXP3+ Tregare associated with an allergic response. The important role of the transcription factor FOXP3 for maintaining immune tolerance stems for multiple basic studies, mainly in experimental models. This importance of FOXP3 + Treg in human disease was underscored by the IPEX syndrome (immunodysregulation, polyendocrinopathy, and enteropathy, X-linked). In IPEX patients a genetic mutation causes the FOXP3 transcription factor to be defective. Patients with IPEX have symptoms that fit both generalized autoimmunity and allergy (Bennett et al., 2001; Patel, 2001). The relevance of FOX P3 Treg has been extensively demonstrated in mice models, showing an inverse correlation to Treg and diseases like RA, inflammatory bowel disease, MS, and IDDM (Shevach, 2000; Fontenot et al., 2003; Sakaguchi, 2005). Not only in autoimmune diseases but also in allergic disease various studies have suggested a possible defective suppressive function of Tregs (Viglietta et al., 2004; Sakaguchi et al., 2006). In addition to the bee keeper model also the season-dependent antigen exposure during the pollen season offers a model to study responses in the same individuals with and without exposure. Whereas in several studies it was shown that both non-allergic as allergic individuals have CD4+CD25+ Treg, in the allergic subjects, these cells still produced IL-5 and IL13 cytokines (Grindebacke et al., 2004; Ling et al., 2004). Further related experiments demonstrated that both dose and type of allergen appear to have effects on the ability of CD4+CD25+ T cells to suppress responses. At the time of these studies $\mathrm{CD} 25^{\mathrm{b}}$ expression on CD4 T cells was used as a surrogate marker of FOXP3+ Treg. Later studies using FOXP3 as a direct marker seemed to confirm these data. During venom immunotherapy the increased allergen-specific IgG4 and reduced IgE correlated with circulating FOXP3 positive Treg (Pereira-Santos et al., 2008). A recent study even suggested that Treg function may be impaired in patients with allergic diseases and that this function can be enhanced by specific immunotherapy (Palomares et al., 2010).

Thus, altogether, there are ample suggestions that the presence of allergen-specific $\mathrm{T}$ cells with a regulatory phenotype (either expressing FOXP3, and/or capable of producing IL-10 and TGF$\beta)$ may have a beneficial effect on allergic diseases. However in some atopic diseases, like atopic dermatitis and asthma, the specific trigger is often not known. This raises the question whether methods can be identified to improve the Treg repertoire, when the triggering allergen is unknown. Studies from other inflammatory diseases, like JIA and RA, have suggested that a certain group of antigens, called HSPs, are present at the site of inflammation and may have such a beneficial effect on the $\mathrm{T}$ cell repertoire.

\section{HEAT SHOCK PROTEINS}

The Treg repertoire is both formed in the thymus (so-called natural Treg) and generated in the periphery upon encounter with an antigen (induced or adaptive Treg). Both self and non-self antigens can induce Treg in the periphery, although the repertoire of Treg might be biased toward self antigens (Romagnoli et al., 2002).

In 1991, Cohen and Young (1991) proposed that a select group of self antigens is especially important for the maintenance of peripheral tolerance). He described the presence of auto reactive immune responses in a healthy individual to a limited set of self molecules, formed by auto reactive $\mathrm{T}$ cells and antibodies, which he called the immunological homunculus. The self antigens of this "homunculus" are all evolutionary highly conserved between the self and the non-self homolog of these proteins. According to Cohen, the immune system utilizes these self antigens to form an immunological picture of self which is crucial for the balance of the immune system. One of these homunculus' self proteins is human HSP60 (van Eden et al., 2005). HSPs are indeed evolutionarily highly conserved proteins and either present constitutively, functioning as chaperones, or induced upon cell stress caused by, for instance, heat, oxidative stress, and hypoxia (Craig et al., 1993). Several HSPs have been identified and, according to their size, organized into six families: HSP100, HSP90, HSP70, HSP60, HSP40, and HSP10. In this review we focus on the immune responses of HSP60 in atopic disease. It has to be stressed that as only very little data are available right now on HSPs and allergic disease, and thus we need to deduce the role of HSP in atopic disorders mostly on what is known about HSP reactivity on other diseases.

\section{IMMUNITY TO HSPS AND INFLAMMATION}

Humoral and cellular immune responses to HSP60 have been detected both in patients with an inflammatory disease, such as autoimmune and allergic diseases, as well as in healthy subjects. After these initial discoveries the perception was that HSP's may be involved in the development of autoimmunity through antigenis mimicry: an immune response toward a microbial HSP could lead to a cross-reactive response to a self-HSP and thus cause autoimmunity. However, after further studies it quickly became clear that the immune responses toward self HSP60 were more involved in the regulation and not in the induction of autoimmunity. Indeed, a wealth of data obtained in the last decade both in experimental models and from observations in human diseases point to a regulatory role of immunity to self HSP60 (van Eden et al., 2005).

The presence of self-HSP-reactive cells was first shown in animal studies by immunization of rats with mammalian HSP60 (Lopez-Guerrero et al., 1993). Though immunization could induce self-HSP-specific antibodies and T cells, a self-HSP-reactive immune repertoire was also shown to be present in the absence of immunization. The cause for this could be previous contact with homologous bacterial HSPs, for example in the mucosa of the gastro intestinal tract. The first report that immune responses to self HSP60 may have a regulatory role in inflammatory diseases was in mycobacteria-induced adjuvant arthritis. In this model the induction of a self HSP60, cross-reactive T cells response was responsible for the observed protection of HSP60 peptide immune therapy. After these initial findings, protective effects of various (conserved) microbial HSPs were seen in many other experimental disease models, including arthritis, atherosclerosis, allergic encephalomyelitis, and allergic asthma (Anderton et al., 1995; Birnbaum et al., 1998; Harats et al., 2002; Rha et al., 2002).

In vitro experiments show that immune responses modulated by HSPs can result in the induction of various cytokines like IFN $\gamma$ and $\mathrm{TNF} \alpha$, as well as IL-10. HSPs are strong immune modulators and are able to influence the impact and direction of immune responses (Kaufmann et al., 1987). Moreover, HSP60 has the capacity to steer both innate and humoral immunity. 
In human diseases, antibody responses to HSP60 were previously described in skin lesions of patients with Behçets disease, whereas HSP60 has been described as a target for T-cells in autoimmune diseases such as IDDM and JIA (Albani et al., 1995b; Ergun et al., 2001; Raz et al., 2001). Data in the experimental models have pointed out that the protective effect of HSP60 was independent of an antigenic relationship (antigen mimicry) between HSP60 and the disease-inducing antigen. Instead it seemed that HSP60 could confer protection through so-called bystander suppression (Horner et al., 2001; Larche et al., 2006). Inflammation causes local damage and cell stress leading to upregulation of stress proteins such as HSP60. Next, these bystander (self) antigens can become the target of subsequent, possibly suppressive immune responses. So, it is possible that immune responses to HSPs could be involved in the control of human chronic inflammatory diseases that have distinct, although as-yet-unknown, initiating auto-antigens, or even allergens.

\section{HSP RESPONSES IN EARLY LIFE}

Apparently, responses to HSP60 are important for maintaining peripheral tolerance in the adult immune system. It is unknown when during live these specific T cells arise. It would seem reasonable to expect that they are primed after birth upon encounter with homologous microbial HSP in the gut. However, there are indications that self HSP60 reactivity is present at birth. In a study by Ramage et al. (1999) it was shown that cord blood cells proliferate in response to an in vitro challenge with the self HSP60. This supported the hypothesis that this reactivity is part of the normal naive immune repertoire. A more recent study by Merbl et al. (2007) put these findings also in a different perspective. They found that normal cord blood contains IgM and IgA auto-antibodies directed against a relatively uniform set of auto-antigens, such as auto-antigens related to immune regulation such as HSP60. This obviously benign autoimmune self reactivity, present at birth, may have a dual function. On the one hand it may provide the basis for autoimmunity in later life, while on the other hand the "inborn" autoimmunity to regulatory self antigens such as HSP60 may actually serve to protect against autoimmune disease. Intrigued by these studies, we questioned whether CD4+ T cells specific for HSP60 are already detectable at birth before exposure to the microbial flora, and if so, to what type of immune response these "inborn" autoreactive CD4+ T cells have upon exposure to the self antigen HSP60. We found that HSP60 specific T cells are indeed present at birth. Moreover, stimulation of CBMC with HSP60 leads to CD4+ T cell proliferation and cytokine production, and induces $\mathrm{T}$ cells with an in vitro regulatory phenotype that are functionally suppressive (Aalberse et al., 2011).

\section{HSP60 AND ALLERGY}

Thus, HSP60 is a self-protein, recognized already at birth in healthy subjects, but also in individuals with chronic inflammatory diseases. Thereby a correlation between self-HSP reactivity and diminished disease activity is seen both in experimental as in human autoimmunity. This has already led to the successful exploration of HSP60 immune therapy in human disease, firstly in IDDM. It is not known yet if the levels and responses to HSP60 are different in individuals developing chronic inflammatory disease later in life.
For once, priming of HSP60 T cell responsiveness takes places primarily in the gut through contact with microbial HSP60 (van Eden et al., 2005). Thus, priming of HSP60 immunity early in life through contact with microbiota leads to more self HSP60 mediated immune regulation. This could be one of possibly multiple mechanisms that explain why individuals exposed to more microbial triggers early in life, could be less prone to develop immune mediated diseases. Thus it may very well fit the concept of the hygiene hypothesis.

For that reason we set out to study the role of HSP60 immunity in human atopic diseases. Obviously the first pre-requisite for a potential role of self HSP60 in dermatitis is the (preferably increased) expression of HSP60 at the site of inflammation. Indeed we were able to show that self HSP60 is increased expressed in the skin of patients with atopic dermatitis (Kapitein and Aalberse submitted for publication). Moreover, in vitro stimulation with self HSP60 induced FOXP3 positive T cells, as well as T cells producing IL-10 and IFN- $\gamma$.

It has to be emphasized that this increased expression by no means is very specific for atopic diseases (Seung et al., 2007). Still it could be highly relevant for atopic disease as the characterization of an antigen present at the site of inflammation, without being the disease-causing antigen has therapeutic possibilities through, as previously mentioned, "antigen driven bystander suppression." Bystander suppression as a mechanism is especially important in human autoimmune diseases, because often the immunizing trigger is unknown.

Theoretically, in allergic diseases this could also be an interesting option for intervention. Although often at least one of the allergens triggering the disease is known, mono-sensitization is rare which would imply multi-antigen immune therapy. Immune therapy with a single bystander antigen might undermine this issue.

\section{NOVEL IMMUNE THERAPEUTIC POSSIBILITIES IN ALLERGIC DISEASE}

Various novel immune therapeutic approaches to diminish allergic symptoms have been or are being studied. Of these new interventions, blocking of effector cytokines (such as IL-4 and IL-5) and IgEis the most important. As IL-5 is important for the priming and survival of eosinophils and these cells play an important role in the pathophysiology of allergic disease, blocking IL-5 seemed logical. However only a highly selected patient group with severe asthma, shown as sputum eosinophilia, had profit from this therapy (Busse et al., 2010). Also blocking IL-4 and IL-13 has not yet been shown to be of clinical benefit in asthma (Oh et al., 2010). Thus, so far, the experiences with blocking antibodies to effector cytokines suggest that either the cytokines cannot be fully blocked or that not one of these cytokines is solely responsible for the allergic response. As mentioned above in recent years Th2 induction cytokines have been described among which IL-25. IL25 is strongly elevated in a subgroup of peanut allergic subjects (Aalberse et al., submitted for publication). Moreover, in mouse models blocking IL-25 has a positive effect on bronchial hyperreactivity (Ballantyne et al., 2007). Apart from blocking cytokines that are important in the pathophysiology of allergic disease, in the last decade various studies in asthmatic patients have been 
performed in which an IgE-blocker was used (Rodrigo et al., 2011). Although the first results look promising, the effect is not present in all patients, underlining again the complexity of chronic allergic diseases.

Antigen SIT, in which an allergic individual is exposed to increasing doses of the allergen triggering disease, has been used for over a century. It is one of the earliest and most effective forms of human immune therapy. Although for long the mechanisms behind this clearly effective immune intervention was not fully understood, we now know that IgG4, IL-10, and Treg probably play an important role. A disadvantage of this approach in which the eliciting protein is used, is the chance of a severe anaphylactic reaction, as has been described following immune therapy in peanut allergic subjects (Reid et al., 1993).

To tackle this issue, recent work has focused on allergy peptide therapy, showing good results. Mice studies showed that after

\section{REFERENCES}

Aalberse, J. A., Kapitein, B., de Roock, S., Klein, M. R., de Jager, W., van der Zee, R., Hoekstra, M. O., van Wijk, F., and Prakken, B. J. (2011). Cord blood CD4+ $\mathrm{T}$ cells respond to self heat shock protein 60 (HSP60). PLoS ONE 6, e24119. doi:10.1371/journal.pone.0024119

Abulafia-Lapid, R., Elias, D., Raz, I., Keren-Zur, Y., Atlan, H., and Cohen, I. R. (1999). T cell proliferative responses of type I diabetes patients and healthy individuals to human hsp60 and its peptides. J. Autoimmun. 12, 121-129.

Akdis, C. A., and Blaser, K. (1999). IL10 -induced anergy in peripheral $\mathrm{T}$ cell and reactivation by microenvironmental cytokines: two key steps in specific immunotherapy. FASEB J. 13, 603-609.

Akdis, M., Verhagen, J., Taylor, A., Karamloo, F., Karagiannidis, C., Crameri, R., Thunberg, S., Deniz, G., Valenta, R., Fiebig, H., Kegel, C., Disch, R., Schmidt-Weber, C. B., Blaser, K., and Akdis, C. A. (2004). Immune responses in healthy and allergic individuals are characterized by a fine balance between allergenspecific $\mathrm{T}$ regulatory 1 and $\mathrm{T}$ helper 2 cells. J. Exp. Med. 199, 1567-1575.

Albani, S., Keystone, E. C., Nelson, J. L., Ollier, W. E., La Cava, A., Montemayor, A. C., Weber, D. A., Montecucco, C., Martini, A., and Carson, D. A. (1995a). Positive selection in autoimmunity: abnormal immune responses to a bacterial dnaJ antigenic determinant in patients with early rheumatoid arthritis. Nat. Med. 1, 448-452.

Albani, S., Keystone, E. C., Nelson, J. L., Ollier, W. E., La, C. A., Montemayor, A. C., Weber, D. A., Montecucco, C., Martini, A., and Carson,
D. A. (1995b). Positive selection in autoimmunity: abnormal immune responses to a bacterial dnaJ antigenic determinant in patients with early rheumatoid arthritis. Nat. Med. 1, 448-452.

Anderton, S. M., van der Zee, R., Prakken, B., Noordzij, A., and van Eden, W. (1995). Activation of T cells recognizing self $60-\mathrm{kD}$ heat shock protein can protect against experimental arthritis. J. Exp. Med. 181, 943-952.

Angkasekwinai, P., Chang, S. H., Thapa, M., Watarai, H., and Dong, C. (2010). Regulation of IL-9 expression by IL-25 signaling. Nat. Immunol. 11, 250-256.

Ballantyne, S. J., Barlow, J. L., Jolin, H. E., Nath, P., Williams, A. S., Chung, K. F., Sturton, G., Wong, S. H., and McKenzie, A. N. (2007). Blocking IL-25 prevents airway hyperresponsiveness in allergic asthma. J. Allergy

Bennett, C. L., Christie, J., Ramsdell, F., Brunkow, M. E., Ferguson, P. J., Whitesell, L., Kelly, T. E., Saulsbury, F. T., Chance, P. F., and Ochs, H. D. (2001). The immune dysregulation, polyendocrinopathy, enteropathy, X-linked syndrome (IPEX) is caused by mutations of FOXP3. Nat. Genet. 27, 20-21.

Birnbaum, G., Kotilinek, L., Miller, S. D., Raine, C. S., Gao, Y. L., Lehmann, P. V., and Gupta, R. S. (1998). Heat shock proteins and experimental autoimmune encephalomyelitis. II: environmental infection and extra-neuraxial inflammation alter the course of chronic relapsing encephalomyelitis. J. Neuroimmunol. 90, 149-161.

Bodner, C., Godden, D., and Seaton, A. (1998). Family size, childhood infections and atopic diseases. The Clin. Immunol. 120, 1324-1331.

immunization with Der $\mathrm{p} 2$, the house dust mite allergen, downregulation of $\mathrm{T}$ cell and antibody responses was seen to Der $\mathrm{p} 2$. Similar results were seen using Fel d 1 (cat allergen) and Bet v 1 (birch allergen) peptide therapy. As most patients are not sensitized to just one allergen, it is now studied if combination immune therapy is also effective. Another approach is the use of a peptide of an antigen present at the site of inflammation, without being the triggering antigen. This is the concept of the previous mentioned antigen bystander suppression model (Horner et al., 2001; Larche et al., 2006).

Based on the development of immune therapies usingHSP60 for other human inflammatory diseases and encouraged by recent data showing that HSP60 expression is increased in the skin in patients with atopic dermatitis, it is tempting to suggest that HSP60 may also be a potential candidate for bystander therapy in allergic diseases.

Aberdeen WHEASE Group. Thorax $53,28-32$.

Braun-Fahrlander, C., Riedler, J., Herz, U., Eder, W., Waser, M., Grize, L., Maisch, S., Carr, D., Gerlach, F., Bufe, A., Lauener, R. P., Schierl, R., Renz, H., Nowak, D., and von Mutius, E. (2002). Environmental exposure to endotoxin and its relation to asthma in school-age children. N. Engl. J. Med. 347, 869-877.

Busse, W. W., Ring, J., Huss-Marp, J., and Kahn, J. E. (2010). A review of treatment with mepolizumab, an antiIL-5 $\mathrm{mAb}$, in hypereosinophilic syndromes and asthma. J. Allergy Clin. Immunol. 125, 803-813.

Chen, L., Martinez, O., Overbergh, L., Mathieu, C., Prabhakar, B. S., and Chan, L. S. (2004). Early upregulation of Th2 cytokines and late surge of Thl cytokines in an atopic dermatitis model. Clin. Exp. Immunol. 138, 375-387.

Cohen, I. R., and Young, D. B. (1991). Autoimmunity, microbial immunity and the immunological homunculus. Immunol. Today 12, 105-110.

Craig, E. A., Gambill, B. D., and Nelson, R. J. (1993). Heat shock proteins: molecular chaperones of protein biogenesis. Microbiol. Rev. 57, 402-414.

de Kleer, I. M., Kamphuis, S. M., Rijkers, G. T., Scholtens, L., Gordon, G., de Jager, W., Hafner, R., van de Zee, R., van Eden, W., Kuis, W., and Prakken, B. J. (2003). The spontaneous remission of juvenile idiopathic arthritis is characterized by $\mathrm{CD} 30+\mathrm{T}$ cells directed to human heat-shock protein 60 capable of producing the regulatory cytokine interleukin-10. Arthritis Rheum. 48, 2001-2010.

de Kleer, I. M., Wedderburn, L. R., Taams, L. S., Patel, A., Varsani, H., Klein, M., de Jager, W., Pugayung,
G., Giannoni, F., Rijkers, G., Albani, S., Kuis, W., and Prakken, B. (2004). $\mathrm{CD} 4+\mathrm{CD} 25$ bright regulatory $\mathrm{T}$ cells actively regulate inflammation in the joints of patients with the remitting form of juvenile idiopathic arthritis. J. Immunol. 172, 6435-6443.

Del Prete, G. (1992). Human Th1 and Th2 lymphocytes: their role in the pathophysiology of atopy. Allergy 47 , 450-455.

Devos, S., Cormont, F., Vrtala, S., Hooghe-Peters, E., Pirson, F., and Snick, J. (2006). Allergen-induced interleukin-9 production in vitro: correlation with atopy in human adults and comparison with interleukin-5 and interleukin-13. Clin. Exp. Allergy 36, 174-182.

Ergun, T., Ince, U., Eksioglu-Demiralp, E., Direskeneli, H., Gurbuz, O., Gurses, L., Aker, F., and Akoglu, T. (2001). HSP 60 expression in mucocutaneous lesions of Behcet's disease. J. Am. Acad. Dermatol. 45, 904-909.

Falcone, F. H., Knol, E. F., and Gibbs, B. F. (2011). The role of basophils in the pathogenesis of allergic disease. Clin. Exp. Allergy 41, 939-947.

Fontenot, J. D., Gavin, M. A., and Rudensky, A. Y. (2003). Foxp3 programs the development and function of $\mathrm{CD} 4+\mathrm{CD} 25+$ regulatory $\mathrm{T}$ cells. Nat. Immunol. 4, 330-336.

Grindebacke, H., Wing, K., Andersson, A. C., Suri-Payer, E., Rak, S., and Rudin, A. (2004). Defective suppression of Th2 cytokines by CD4CD25 regulatory $\mathrm{T}$ cells in birch allergics during birch pollen season. Clin. Exp. Allergy 34, 1364-1372.

Harats, D., Yacov, N., Gilburd, B., Shoenfeld, Y., and George, J. (2002). Oral tolerance with heat shock protein 65 attenuates Mycobacterium tuberculosis-induced and high-fat-diet-driven 
atherosclerotic lesions. J. Am. Coll. Cardiol. 40, 1333-1338.

Hauber, H. P., Bergeron, C., Toda, M., Kontolemos, M., Holroyd, K. J., Levitt, R. C., and Hamid, Q. (2007). Up-regulation of interleukin-9 and the interleukin-9-associated calcium-activated chloride channel hCLCA1 in nasal mucosa following in vivo allergen challenge. Allergy Asthma Clin.Immunol. 3, 19-23.

Horner, A. A., Datta, S. K., Takabayashi, K., Belyakov, I. M., Hayashi, T., Cinman, N., Nguyen, M. D., Van Uden, J. H., Berzofsky, J. A., Richman, D. D., and Raz, E. (2001). Immunostimulatory DNA-based vaccines elicit multifaceted immune responses against HIV at systemic and mucosal sites. J. Immunol. 167, 1584-1591.

Hvid, M., Vestergaard, C., Kemp, K., Christensen, G. B., Deleuran, B., and Deleuran, M. (2011). IL-25 in atopic dermatitis: a possible link between inflammation and skin barrier dysfunction? J. Invest. Dermatol. 131, 150-157.

Jarvis, D., Chinn, S., Luczynska, C., and Burney, P. (1997). The association of family size with atopy and atopic disease. Clin. Exp. Allergy 27, 240-245.

Kaufmann, S. H., Vath, U., Thole, J. E., Van Embden, J. D., and Emmrich, F. (1987). Enumeration of T cells reactive with Mycobacterium tuberculosis organisms and specific for the recombinant mycobacterial 64$\mathrm{kDa}$ protein. Eur. J. Immunol. 17, 351-357.

Krug, N., Madden, J., Redington, A. E., Lackie, P., Djukanovic, R., Schauer, U., Holgate, S. T., Frew, A. J., and Howarth, P. H. (1996). T-cell cytokine profile evaluated at the single cell level in BAL and blood in allergic asthma. Am. J. Respir. Cell Mol. Biol. 14, 319-326.

Larche, M. (2007). Regulatory T cells in allergy and asthma. Chest 132, 1007-1014.

Larche, M., Akdis, C. A., and Valenta, R. (2006). Immunological mechanisms of allergen-specific immunotherapy. Nat. Rev. Immunol. 6, 761-771.

Ling, E. M., Smith, T., Nguyen, X. D., Pridgeon, C., Dallman, M., Arbery, J., Carr, V. A., and Robinson, D. S. (2004). Relation of CD4+CD25+ regulatory $\mathrm{T}$-cell suppression of allergen-driven T-cell activation to atopic status and expression of allergic disease. Lancet 363, 608-615.

Lloyd, C. M., and Hessel, E. M. (2010). Functions of T cells in asthma: more than just $\mathrm{T}(\mathrm{H}) 2$ cells. Nat. Rev. Immunol. 10, 838-848.
Lopez-Guerrero, J. A., Lopez-Bote, J. P., Ortiz, M. A., Gupta, R. S., Paez, E., and Bernabeu, C. (1993). Modulation of adjuvant arthritis in Lewis rats by recombinant vaccinia virus expressing the human 60-kilodalton heat shock protein. Infect. Immun. 61, 4225-4231.

Merbl, Y., Zucker-Toledano, M., Quintana, F. J., and Cohen, I. R. (2007). Newborn humans manifest autoantibodies to defined self molecules detected by antigen microarray informatics. J. Clin. Invest. 117, 712-718.

Mosmann, T. R., and Coffman, R. L. (1989). TH1 and TH2 cells: different patterns of lymphokine secretion lead to different functional properties. Annu. Rev. Immunol. 7, 145-173.

Nograles, K. E., Zaba, L. C., Shemer, A., Fuentes-Duculan, J., Cardinale, I., Kikuchi, T., Ramon, M., Bergman, R., Krueger, J. G., and GuttmanYassky, E. (2009). IL-22-producing T22 T cells account for upregulated IL-22 in atopic dermatitis despite reduced IL-17-producing TH17 T cells. J. Allergy Clin. Immunol. 123, 1244-1252.

Oh, C. K., Geba, G. P., and Molfino, N. (2010). Investigational therapeutics targeting the IL-4/IL-13/STAT-6 pathway for the treatment of asthma. Eur. Respir. Rev. 19, 46-54.

Oliphant, C. J., Barlow, J. L., and McKenzie, A. N. (2011). Insights into the initiation of type 2 immune responses. Immunology 134, 378-385.

Ong, P. Y., and Leung, D. Y. (2006). Immune dysregulation in atopic dermatitis. Curr. Allergy Asthma Rep. 6, 384-389.

Ozdemir, C., Akdis, M., and Akdis, C. A. (2010). T-cell response to allergens. Chem. Immunol. Allergy 95, 22-44.

Palomares, O., Yaman, G., Azkur, A. K., Akkoc, T., Akdis, M., and Akdis, C. A. (2010). Role of Treg in immune regulation of allergic diseases. Eur. J. Immunol. 40, 1232-1240.

Patel, D. D. (2001). Escape from tolerance in the human X-linked autoimmunity-allergic disregulation syndrome and the Scurfy mouse. J. Clin. Invest. 107, 155-157.

Peat, J. K., van den Berg, R. H., Green, W. F., Mellis, C. M., Leeder, S. R., and Woolcock, A. J. (1994). Changing prevalence of asthma in Australian children. BMJ 308, 1591-1596.

Pereira-Santos, M. C., Baptista, A. P., Melo, A., Alves, R. R., Soares, R. S., Pedro, E., Pereira-Barbosa, M., Victorino, R. M., and Sousa, A.
E. (2008). Expansion of circulating Foxp3+D25bright CD4+ T cells during specific venom immunotherapy. Clin. Exp. Allergy 38, 291-297.

Platts-Mills, T. A., Woodfolk, J. A., Erwin, E. A., and Aalberse, R. (2004). Mechanisms of tolerance to inhalant allergens: the relevance of a modified Th2 response to allergens from domestic animals. Springer Semin. Immunopathol. 25, 271-279.

Pockley, A. G. (2003). Heat shock proteins as regulators of the immune response. Lancet 362, 469-476.

Prakken, B. J., Samodal, R., Le, T. D., Giannoni, F., Yung, G. P., Scavulli, J., Amox, D., Roord, S., de Kleer, I., Bonnin, D., Lanza, P., Berry, C., Massa, M., Billetta, R., and Albani, S. (2004). Epitope-specific immunotherapy induces immune deviation of proinflammatory $\mathrm{T}$ cells in rheumatoid arthritis. Proc. Natl. Acad. Sci. U.S.A. 101, 4228-4233.

Ramage, J. M., Young, J. L., Goodall, J. C., and Gaston, J. S. (1999). T cell responses to heat-shock protein 60 : differential responses by $\mathrm{CD} 4+\mathrm{T}$ cell subsets according to their expression of CD45 isotypes. J. Immunol. 162, 704-710.

Raz, I., Elias, D., Avron, A., Tamir, M., Metzger, M., and Cohen, I. R. (2001). Beta-cell function in new-onset type 1 diabetes and immunomodulation with a heat-shock protein peptide (DiaPep277): a randomised, doubleblind, phase II trial. Lancet 358 , 1749-1753.

Reid, M. J., Lockey, R. F., Turkeltaub, P. C., and Platts-Mills, T. A. (1993). Survey of fatalities from skin testing and immunotherapy 1985-1989. J. Allergy Clin. Immunol. 92(Pt 1), 6-15.

Rha, Y. H., Taube, C., Haczku, A., Joetham, A., Takeda, K., Duez, C., Siegel, M., Aydintug, M. K., Born, W. K., Dakhama, A., and Gelfand, E. W. (2002). Effect of microbial heat shock proteins on airway inflammation and hyperresponsiveness. $J$. Immunol. 169, 5300-5307.

Rodrigo, G. J., Neffen, H., and CastroRodriguez, J. A. (2011). Efficacy and safety of subcutaneous omalizumab vs placebo as add-on therapy to corticosteroids for children and adults with asthma: a systematic review. Chest 139, 28-35.

Romagnoli, P., Hudrisier, D., and van Meerwijk, J. P. (2002). Preferential recognition of self antigens despite normal thymic deletion of $\mathrm{CD} 4(+) \mathrm{CD} 25(+)$ regulatory $\mathrm{T}$ cells. J. Immunol. 168, 1644-1648.

Saenz, S. A., Noti, M., and Artis, D. (2010). Innate immune cell populations function as initiators and effectors in Th2 cytokine responses. Trends Immunol. 31, 407-413.

Sakaguchi, S. (2005). Naturally arising Foxp3-expressing CD25+CD4+ regulatory $\mathrm{T}$ cells in immunological tolerance to self and non-self. Nat. Immunol. 6, 345-352.

Sakaguchi, S., Setoguchi, R., Yagi, H., and Nomura, T. (2006). Naturally arising Foxp3-expressing $\mathrm{CD} 25+\mathrm{CD} 4+$ regulatory $\mathrm{T}$ cells in self-tolerance and autoimmune disease. Curr. Top. Microbiol. Immunol. 305, 51-66.

Seung, N. R., Park, E. J., Kim, C. W., Kim, K. H., Kim, K. J., Cho, H. J., and Park, H. R. (2007). Comparison of expression of heat-shock protein 60 , Toll-like receptors 2 and 4 , and T-cell receptor gammadelta in plaque and guttate psoriasis. J. Cutan. Pathol. 34, 903-911.

Sheikh, A., Smeeth, L., and Hubbard, R. (2003). There is no evidence of an inverse relationship between Th2 mediated atopy and Th1 mediated autoimmune disorders: Lack of support for the hygiene hypothesis. $J$. Allergy Clin. Immunol. 111,131-135.

Shevach, E. M. (2000). Regulatory T cells in autoimmmunity*. Апnи. Rev. Immunol. 18, 423-449.

Sokol, C. L., Chu, N. Q., Yu, S., Nish, S. A., Laufer, T. M., and Medzhitov, R. (2009). Basophils function as antigen-presenting cells for an allergen-induced $\mathrm{T}$ helper type 2 response. Nat. Immunol. 10, 713-720.

Soroosh, P., and Doherty, T. A. (2009). Th9 and allergic disease. Immunology $127,450-458$

Souwer, Y., Szegedi, K., Kapsenberg, M. L., and de Jong, E. C. (2010). IL-17 and IL-22 in atopic allergic disease. Curr. Opin. Immunol. 22, 821-826.

Strachan, D. P. (1989). Hay fever hygiene, and household size. $B M J$ 299, 1259-1260.

Taylor, A., Verhagen, J., Blaser, K., Akdis, M., and Akdis, C. A. (2006). Mechanisms of immune suppression by interleukin-10 and transforming growth factor-beta: the role of $\mathrm{T}$ regulatory cells. Immunology $117,433-442$

Tiemessen, M. M., Van Ieperen-Van Dijk, A. G., Bruijnzeel-Koomen, C. A., Garssen, J., Knol, E. F., and Van Hoffen, E. (2004). Cow's milkspecific T-cell reactivity of children with and without persistent cow's milk allergy: key role for IL-10. J. Allergy Clin. Immunol. 113, 932-939. Umetsu, D. T., Akbari, O., and Dekruyff, R. H. (2003). Regulatory T cells 
control the development of allergic disease and asthma. J. Allergy Clin. Immunol. 112, 480-487.

van der Neut, K. M., Schuurman, J., Losen, M., Bleeker, W. K., MartinezMartinez, P., Vermeulen, E., den Bleker, T. H., Wiegman, L., Vink, T., Aarden, L. A., De Baets, M. H., van de Winkel, J. G., Aalberse, R. C., and Parren, P. W. (2007). Antiinflammatory activity of human IgG4 antibodies by dynamic Fab arm exchange. Science 317, 1554-1557.

van Eden, W., van der Zee, R., and Prakken, B. (2005). Heat-shock proteins induce T-cell regulation of chronic inflammation. Nat. Rev. Immunol. 5, 318-330.

Viglietta, V., Baecher-Allan, C., Weiner, H. L., and Hafler, D. A. (2004).
Loss of functional suppression by $\mathrm{CD} 4+\mathrm{CD} 25+$ regulatory $\mathrm{T}$ cells in patients with multiple sclerosis. $J$. Exp. Med. 199, 971-979.

von Mutius, E., Illi, S., Hirsch, T., Leupold, W., Keil, U., and Weiland, S. K. (1999). Frequency of infections and risk of asthma, atopy and airway hyperresponsiveness in children. Eur. Respir. J. 14, 4-11.

Wegmann, T. G., Lin, H., Guilbert, L., and Mosmann, T. R. (1993). Bidirectional cytokine interactions in the maternal-fetal relationship: is successful pregnancy a $\mathrm{TH} 2$ phenomenon? Immunol. Today 14, 353-356.

Wickens, K., Crane, J., Pearce, N., and Beasley, R. (1999). The magnitude of the effect of smaller family sizes on the increase in the prevalence of asthma and hay fever in the United Kingdom and New Zealand. J. Allergy Clin. Immunol. 104(Pt 1), 554-558.

Yamanaka, K., and Mizutani, H. (2011). The role of cytokines/chemokines in the pathogenesis of atopic dermatitis. Curr. Probl. Dermatol. 41, 80-92.

Yazdanbakhsh, M., Kremsner, P. G., and van Ree, R. (2002). Allergy, parasites, and the hygiene hypothesis. Science 296, 490-494.

Conflict of Interest Statement: The authors declare that the research was conducted in the absence of any commercial or financial relationships that could be construed as a potential conflict of interest.
Received: 19 January 2012; paperpending published: 16 February 2012; accepted: 14 May 2012; published online: 31 May 2012.

Citation: Aalberse JA, Prakken BJ and Kapitein B (2012) HSP: bystander antigen in atopic diseases? Front. Immun. 3:139. doi: 10.3389/fimmu.2012.00139 This article was submitted to Frontiers in Inflammation, a specialty of Frontiers in Immunology.

Copyright (๑) 2012 Aalberse, Prakken and Kapitein. This is an open-access article distributed under the terms of the Creative Commons Attribution Non Commercial License, which permits noncommercial use, distribution, and reproduction in other forums, provided the original authors and source are credited. 